\title{
Essais
}

ESSAIS

Revue interdisciplinaire d'Humanités

$10 \mid 2016$

Faire-valoir et seconds couteaux

\section{Sidekicking the sidekick: from a reassuring stable position to a disturbing narrative process}

Introduction

Nathalie Jaëck

\section{OpenEdition}

\section{Journals}

Electronic version

URL: http://journals.openedition.org/essais/3712

DOI: $10.4000 /$ essais.3712

ISSN: 2276-0970

Publisher

École doctorale Montaigne Humanités

Printed version

Date of publication: 15 September 2016

Number of pages: $7-14$

ISBN: 978-2-9544269-9-0

ISSN: $2417-4211$

\section{Electronic reference}

Nathalie Jaëck, « Sidekicking the sidekick: from a reassuring stable position to a disturbing narrative process », Essais [Online], 10 | 2016, Online since 15 October 2020, connection on 21 October 2020 URL : http://journals.openedition.org/essais/3712 ; DOI : https://doi.org/10.4000/essais.3712 


\section{Sidekicking the sidekick: \\ from a reassuring stable position \\ to a disturbing narrative process}

\section{Introduction}

Nathalie Jaëck

What is quite remarkable, when one considers the following collection of essays dealing with sidekicks and underlings in English-language literature, film, popular culture and history, is that none of the favourite usual suspects turn up -with the notable exception perhaps of Tonto to the Lone Ranger in the article written by Lionel Larré and Aaron Carr. No long-enduring Watson to domineering Sherlock, no Robin to Batman, no Ron Weasley to Harry Potter, no Hastings to Poirot, no Tinker Bell to Peter Pan, not even a passing tribute to prototypical Sancho Panza, in memoriam. While one could expect the present volume to characterize the figure of the sidekick, to list their typical characteristics through a telling choice of worthy representatives and an inventory of case-studies, the articles frustratingly side-track expectations and certainly do not read as a reference gallery of the most impressive sidekicks and their collective idiosyncrasies.

While one might expect to find in this volume an academic version of the best-selling The Official Sidekick Handbook. How to unleash your inner second banana and find true happiness, where the pair Too Slim and Texas Bix Bender list what it takes to be a perfect sidekick ${ }^{1}$, the different authors thwart easy anticipations, and, each in their respective fields, insist upon questioning obvious characteristics and hierarchies about sidekicks.

Crucially, instead of considering the figure of the sidekick as an identifiable stable position to be circumscribed in detail in order to celebrate these familiar "fool figures in the traditional Shakespearean sense" (Roof 14), the authors

1 In this funny handbook, which basically constitutes an adequate example of the nature of most of the literature on the subject, the authors list elements that have come to constitute our basic shared idea of what a proper sidekick should be -as indeed there are rules to be an adequate, validated sidekick. Among these pieces of advice, one can read such valuable elements as: "Become one with the wallpaper. If your hero has an awkward or embarrassing moment, you disappear." (78); "Be the butt of the joke" (83), in Too Slim \& Texas Bix Bender. The Official Sidekick Handbook. How to unleash your inner second banana and find true happiness. Layton: Gibbs Smith, 2011. 
all explore the ambiguous, mobile and strategic dynamics of such hierarchies. They collectively illustrate how highly unstable the admitted positions are, how they are indeed quite often ironic pretexts to inversions of power. Beyond mere patterns of inversion, they also highlight the mobility that marks these seemingly static pairs and explore the multiple dynamics of these positions. Most importantly, they demonstrate that the sidekick is not so much a typical fixed form, a conservative reproduction of hackneyed and easily listed reassuring functions (comic relief, help to the hero, glorification of his power, truthfulness and permanence ${ }^{2}$ ), as rather a destabilizing force at work.

Endowed with seeming harmlessness, with the "quality of unnoticeableness" (Roof 14), they are able to disturb and subvert dominant modes, to propose alternative narratives, the more so efficient indeed as they seem so easy to discard, or to be patronized over. The following papers are thus different illustrations of the fact that "while the sidekick is almost always subservient to the main character, it enriches and complicates every narrative through which it rides" (Cameron 1).

Decisively, they also analyse the critical links between narration and the production of sidekicks: reading the collection of essays, it becomes obvious that the authors are interested in sidekicking as a process, in as much as it is often a product of discourse. They analyse how some populations, some classes, some genders are deliberately sidekicked, placed in a subservient, secondary and minor position -or alternately how they can decide to sidekick themselves, in order to occupy a sort of unassuming back base, as harmless decoys: they deliberately choose to operate from this inconspicuous off-centre position in order to subvert the major mode of the narration or of the institution they are supposed to serve and glorify. They can also decide to "unsidekick" themselves and to claim prominence and power, like the heiresses to Biblical female characters in the contemporary British novels analysed in Ewa Rychter's paper.

More than sidekicks then, more than the reassuring static figures that take part in a binary hierarchical organization and people our imagination with unassuming endearing characters, the present volume defines sidekicking as a tactical activity and dissenting process.

Binary pairs become not only deceitful but also eminently mobile; duality gives way to multiplicity as sidekicks uncannily grow and multiply, until they completely dispense with the necessity of a centre; sidekicking is dealt with essentially as a production of discourse, and the major contribution of this volume is probably to be found in the exploration of the links between sidekicks and narration.

2 In his Preface to Sidekicks in American Literature by Ann Cameron (Lewiston: The Edwin Mellen Press, 2002), Alan T. McKenzie insists that Sancho Panza is the vivid matrix of such a static conception of sidekicks: "Sancho Panza is a convenient and fruitful prototype as he served most of the various narrative functions the sidekick could fulfil: messenger, agent, explainer, sounding board, mentor, articulator of alternative (and often more sensible) values, comic relief, or butt (and thus receiver of arrows, blows or kicks), devil's advocate, and, most importantly, grounder in realism)." (ii) 
In her article, "A $\mathrm{A}$ working class hero's sidekick is something to be': sidekicks and underlings in British social realist cinema (1956-2014)", Anne-Lise Marin-Lamellet demonstrates, through a sweeping analysis of over twenty films, the vital importance of the presence of the sidekick for the working class hero in contemporary British films. She links that crucial presence both to the genre of social realist cinema and to the notion of class, highlighting that the significance of the sidekick cannot be separated from genre expectations and from class structures. It becomes obvious that the sidekick is produced and determined by overhanging structures, and serves an ideological function: in the British working class as it is pictured in these films, dispensing with the typical obedient sidekick in order to replace him with a multiplicity of equals amounts to dispensing with typical hierarchies by processes of levelling and companionship. Indeed, far from being a mere underling or foil, the sidekick often proves to be more of a double or a partner in the couple he constitutes with the hero. Even more importantly, the ranked individual relationship emblematized by the hero/sidekick couple is dissolved into group dynamics and solidarities, as these films pluralise sidekicks: the hero is then just the "first among equals" in a group of multiple sidekicks, and such a move is of course to be interpreted as an alternative to strategies of domination, as a praise of collaboration, collective action and solidarity.

Marin-Lamellet's analysis insists that this process of multiplication is part of a wider modern phenomenon, and indeed, sidekicks and underlings are gradually gaining ground in fiction and film, they occupy centre stage and quite often dispense with the domineering figure of the hero. In some instances, particularly among contemporary popular genre fiction, the hero is so amounting sidekicked that he actually becomes kicked to the side, and nearly a comical relic. The buddy movies of Judd Apatow often stage such funny cohorts of highly endearing pathetic sidekicks that pluralise and colonise the elected space of the hero. In many contemporary superhero movies, the typical hero/sidekick pair, as in prototypical Batman/Robin, is replaced by a palatable collection of multiple sidekicks that people the movies, and break with the convention of the unique hero endowed with a foil. In the X-Men series or in The Fantastic Four, hierarchy is replaced by collaboration among equals, while, on a more parodic mode, in Guardians of the Galaxy, a 2014 American movie directed by James Gunn, Gamora, Drax the Destroyer, Groot the tree-like humanoid and Rocket the genetically engineered raccoon team up to mock the heroic pretensions of Star Lord. Sidekicks are there obviously no longer defined as the lesser character in a pair, but as the central multiple focus, the hero being radically done up with in his own very sanctuary -a oxymoronic superhero movie without a hero.

Marin-Lamellet's paper is interesting to contrast with Carr and Larrés Indian Sidekicks and American Identity. They show precisely what strategies of domination are at work in a genre -the Hollywood movies featuring Indians- 
that insists on maintaining the role of the sidekick and on assigning that role to specific populations. It is quite clear in their paper how the role of the sidekick in such films is pre-coded by racial expectations as to what kind of people should be maintained in the circumscribed and secondary role of the sidekick. The sidekick is then manipulated as a defining and discriminative category, with an obvious political agenda -a way to minorize minorities, to maintain them in a hierarchically inferior position. Native American actors are relegated to playing sidekicks, static characters forcing the Indians into the stereotypes associated to them by Western representations, while non-Indian actors are employed to portray the full-blown heroes, which obviously conditions expectations and manipulates identities- typically the very controversial choice of Johnny Depp as Native American warrior Tonto in Gore Verbinski's The Lone Ranger in 2013. The paper also shows how the category has recently acquired some mobility, through an analysis of over a dozen movies. The authors demonstrate how the evolution of Indian characters in Hollywood from villains to sidekicks may be a way for mainstream America to bring into the fold the Indians who, contrary to what was hoped and/or expected, did not vanish, and also to come to terms with that part of their own identity -a process of gradual incorporation perhaps, a way to internalize a duality in the self, and pave the way for a reflexion on the notion of American identity.

Larré and Carr's paper finds two echoes in the present volume -one that develops the purely American side of the issue by concentrating on the dynamics of relegation and power at work in the character that can be considered as the United States' super sidekick, the Vice-President, and one that develops the role of the sidekick in the constitution of the self.

The papers by Pierre-Marie Loizeau and Christopher Griffin, both of which deal with the American Vice-Presidency, provide invaluable analysis about the use and functioning of that institutional sidekick position, and contribute to highlight the multiple and mobile strategies of power that are at work in that seemingly static pair -though they also hint at the potential artificiality of the role play. In this context, Loizeau examines the sidekick as an institutional position, as a status, beyond the individuals that have occupied it; he highlights the subservient role of that function, in which the Vice-President is not a second in command, but literally a sidekick, a "running mate" not chosen as for himself but as part of the package deal, as part of the presidential ticket. Loizeau shows how the Vice-President is a tricky identity, cornered between the unique President and the multiplicity of advisers who organize and reorganize in a more dynamic way. He crucially highlights how an official sidekick can hide a more underground one, by developing the "case of triangulation" specific to the Clinton presidency when Hilary Clinton, the First Lady, not mentioned in the Constitution, not elected, not remunerated, nonetheless side-tracked the Vice-President, and relegated him to third rank. Yet, though 
Griffin agrees that historically, the American Vice-President has had very little power in foreign and defence policy, despite his seat on the National Security Council, he proves that since 2000, the Vice-President has become much more visible as a powerful member of the executive branch. He examines the two cases of Dick Cheney who, after the election of George W. Bush, rapidly became one of the most important, if not the most important single person in the formulation of foreign policy, and of Joe Biden who, with extensive experience on the Senate Foreign Relations Committee as well as a certain expertise in terrorism and Homeland Security, seemed at least on the surface to follow Cheney's example in foreign and defence policy. Beyond the valuable information both articles provide about the American Vice-Presidency, the authors highlight the ambivalence of the position of the sidekick -both a space of relegation and a potentially empowering back base, the more so efficient as it seems unobtrusive.

In his paper on several Frankenstein movies, Its alive and (side-)kicking! Frankenstein's double acts, Jean-François Baillon concentrates on the other aspect of Larré and Carr's paper, exploring the role of sidekicks in representations of the self, defining the sidekick as a potentiality of the hero, as a sort of inner double -an "insidekick" to take up Baillon's brilliant shortcut. While in Mary Shelley's novel, published in 1818, Victor Frankenstein works on his own in his lab, the many movie adaptations or parodies examined by Baillon have obsessively insisted on endowing the scientist with a sidekick. In the process, the sidekicks are not so much opposed foils as expressions of the characters' inner duality: sidekicks then become ways to highlight the different aspects of the personality of the hero, they redouble the identity of Frankenstein, highlight and develop possible streaks. A character in search of a sidekick to better circumscribe himself-or to be allowed the many developments that he does not and cannot recognize as his own, in a sort of Jekyll and Hyde pattern.

The reflexion on identity is further developed in Laurence Machet and Lee Schweininger's paper, "Billy walked and I rode': John and William Bartram Roam the World Over" in which they illustrate the fact that sidekicks are necessary to constructions of the self, and that as such, they are also products of partial narrations of the self. Machet and Schweininger focus on two complementary travel accounts of the same expedition -one by a father, one by a son, where the respective positions as hero and sidekick are proved to depend upon who holds the pen. In 1765, John Bartram (1699-1777), an American-born naturalist that had been commissioned to lead an expedition in order to chart Florida, which Great Britain had recently acquired from Spain, convinced his twenty-six-yearold son William (1739-1823) to accompany him. As the authors examine the expedition through the father and son's respective travel accounts, they come to the conclusion that the sidekick is in fact a product of narration, a function of discourse: just as the "self" or the "I" of the narrative is "a construct, a 
persona, not the person" (Barros 20), the sidekick is more a persona than a character, a useful projection to secure the self. In other words, characters may be sidekicked by others, forced into the persona of the sidekick in order to glorify themselves, and the confrontation of these two accounts is quite telling about the reversibility of the process: the constructed personae and resultant "characters" in the respective travel accounts render John's son William through his father's sometimes humorous accounts a sort of sidekick on what is very much the father's exploratory journey. Conversely, William presents a persona in his own first-person travel account (1791) that is very much that of the hero.

That sidekicking is a narrative process more than a stable objective position, and that the narrator has got virtually all power in manipulating and stabilizing these dynamics is also developed in Paris's paper about the respective positions of Sam and Frodo in The Lord of the Rings. As the subject leading the quest, Frodo is typically presented as the hero and Sam as the sidekick, literally "by his side", a complement to the hero: "But I don't think you need to go alone. Not if you know of anyone you can trust, and who would be willing to go by your side -and that you would be willing to go by your side- and that you would be willing to take into unknown perils." (The Lord of the Rings I, 2) But Paris shows that tables are turned by the fact that Sam becomes the narrator, and decides to cast himself in the persona of the helper -to sidekick himself. As for the Bartrams, the sidekick becomes a strategic position to be either delegated or occupied, according to one's own agenda and priorities- indeed, Sam's success as a narrator depends upon his glorification of Frodo, in his ability to repeat a very efficient narrative stereotype and to please the readers accustomed to the code; casting himself in the position of the faithful dependable sidekick may also be a way to disguise his own thirst for power.

The process described by Paris is indeed similar to one of the essential characteristics of the Holmes/Watson famous prototypical pair: Watson definitely fits the costume of the sidekick to perfection, but that immensely enjoyable static distribution of roles is cunningly complicated by the fact that Watson is the narrator indeed. Though his narrative status could totally enable him to enhance his own role in the resolution of their cases, he systematically underplays it, masochistically minimizing himself, an "I" with no ego. His narration aims at glorifying Holmes's brilliance, and at undermining his own role in the stories: he casts himself as the incompetent though well-meaning sidekick, wallowing in his own deficiencies, and loses no occasion to solidify for the readers the necessary respective roles. Sidekicking himself becomes a very efficient narrative strategy, enabling him both to dazzle the reader with the exploits of his hero-character, and to flatter his sense of superiority by confronting him with an acolyte that is seemingly on the dumb side -himself. Such self-effacing manipulation of the function of the sidekick is totally jubilatory, and illustrates another facet of sidekicking as a narrative strategy. 
In his paper, "Subverting sidekicks -inversions and instability in Kem Nunn's Tapping the Source", Jeffrey Swartwood focuses on documenting and beginning to qualify the sidekick roles within Kem Nunn's Surf Noire narrative, Tapping the Source. Within that emerging genre, it becomes obvious that the dissenting use of leading and secondary figures provides a tentative framework that leaves traditional structures askew. Nunn breaks the character codes of loyalty and hierarchy, as he redistributes and multiplies the roles of sidekicks along different rules than the ones reiterated by the long-standing literary code of by-thebook sidekicks. On top of analyzing processes of inversion and multiplication, Swartwood opens a new interesting line of analysis: in Tapping the Source it is not only the characters that are engaged in a constant unstable redistribution of roles. The sense of insecurity and disorientation is increased by the fact that the several narrative levels themselves disturb their own hierarchy: what seemed to be the major plot is likely to be overrun, overwritten by a secondary plot that takes over, and that suddenly reshuffles the statuses, not only of the characters but of the embedded plots themselves. According to successive viewpoints and to the evolving relative importance of some plots over others, the sidekick becomes what we could call a shared and iridescent status that can be distributed at random, and no longer a meaningful reassuring hierarchy.

In his paper "Les égarés de la narration dans Neverwhere de Neil Gaiman" ("Lost in Narration in Neil Gaiman's Neverwhere"), Aurélien Royer proposes in a similar way that the sidekicks there might well be heroes caught in the wrong stories; he develops the idea that the sidekick figure is not so much relative to that of the hero, as to generic rules and narrative habits, to conventions and choices. There again, Royer is faced with sidekicks that are both proliferating and flamboyant: the young hero, a rather bland unexceptional character at first, caught in the literary tradition of the bildungsroman and acquiring his status very progressively, is characterized against a gallery of colourful helpers that constantly pop up in the novel, minor but all wonderful, secondary but highly striking. It reads as if they had escaped from their own individual stories and temporarily relinquished central roles to be willing accessories to another's story. Reading lues to a missing intertextuality, they hint at the existence of other texts, of other versions -we could say that they read as quotes or extracts that enhance a text that is only provisionally the major text. Neverwhere thus highlights the essential arbitrariness and temporariness of such fixations: it only takes a shift in the narration to subvert seemingly solid hierarchies. In Neverwhere, sidekicks occupy a highly dynamic textual middle and alternative: they are there to support the major story, the major mode of the text, but they also hint at other alternative stories, they open lines of escape in radically different directions. They illustrate Roof's position that "minor characters hint at the possibility of multiple entrances to a text and a wandering away from organization, structure." (Roof 5) They de-concentrate the text, and are also there to value what is eccentric, marginal, outside, 
collateral, and to forcefully insist that there are possible alternatives to the major narration. Their function is to prevent meaning from completely settling, from being stabilized, and to hint at other possible versions of the text. In Neverwhere, the several sidekicks are thus both useful detours, comforting the central narration by performing the typical function of helpers, and threatening short-circuits, as "the minor often provides the elements that clash, undermine, or undo any sense of textual unity or consistency". (Roof 6 )

On this subject, Ewa Rychter strikes a very impressive note. In "We will call the damsel, and enquire at her mouth." Re-writing Biblical Women in Contemporary British Novels", she details how several contemporary British novels rewrite the Bible in ways that reverse and re-distribute the roles played by men and women in the authoritative hypotext narrative. Analysis J. Diski's Only Human: A Comedy (2000) and After These Things (2004), C. Toibin's The Testament of Mary (2012), and M. Roberts's The Wild Girl (1984) and The Book of Mrs Noah (1987) she shows how the nameless wife of Noah, as well as Sarah (Abraham's wife), Rebecca (Isaac's wife), Mary (Jesus' mother) and Mary Magdalene shed their traditional status as underlings and mere sidekicks to their husbands, and come to dominate the narrative, tossing the male heroes into the background. On top of highlighting such a militant reversal that is of course to be interpreted in terms of gender politics, Rychter's analysis shows how the Bible, the ultimate prototypical authoritative text, is dethroned and used as a mere literary sidekick by these contemporary writers: the heroic reference is dealt with as a simple quote to be questioned -sidekicking the conservative Bible for the sake of reformative fiction. Taking the example of the Bible and its gendered patriarchal distribution of roles, Rychter further illustrates that from the beginnings of narration, sidekicking has been a textual effect aiming at maintaining hierarchies - and that it can be undone. These contemporary novels not only fight back for the rehabilitation and empowering of these sidekicked female characters; they also propose a dissident rewriting, a narrative mutation.

If one is thus to generalize from this collection of essays, it seems that the reassuring narrations of typical sidekicks are up and done with: the sense of order and reproduction they flattered seems to have lived, the individual recognizable static figures seem to yield under multiple anonymous peer pressure and these stable stories are now quoted to be used as mere narrative sidekicks to other more dissident narratives, manipulated as static parodies to be questioned. If Watson, Robin and Co still come to mind after reading the volume, it is now partly as static endearing relics of a narrative mode that has grown much more diverse, and that has explored its potential for subversion.

\section{Nathalie Jaëck}

EA 4196 CLIMAS

Université Bordeaux Montaigne Nathalie.Jaeck@u-bordeaux-montaigne.fr 